\title{
A critical evaluation of science outreach via social media: its \\ role and impact on scientists [version 1; peer review: 2
}

\section{approved, 1 approved with reservations]}

\section{Craig McClain¹, Liz Neeley²}

${ }^{1}$ National Evolutionary Synthesis Center, Duke University, 2024 W. Main St. Durham, NC, 27712, USA

${ }^{2}$ COMPASS, University of Washington, College of the Environment, Box 355020 Seattle, WA, 98195, USA

V1 First published: 09 Dec 2014, 3:300

https://doi.org/10.12688/f1000research.5918.1

Latest published: 18 May 2015, 3:300

https://doi.org/10.12688/f1000research.5918.2

\section{Abstract}

The role of scientists in social media and its impact on their careers are not fully explored. While policies and best practices are still fluid, it is concerning that discourse is often based on little to no data, and some arguments directly contradict the available data. Here, we consider the relevant but subjective questions about social media for science outreach (SOSM), specifically: (1) Does a public relations nightmare exist for science?; (2) Why (or why aren't) scientists engaging in social media?; (3) Are scientists using social media well?; and (4) Will social media benefit a scientist's career? We call for the scientific community to create tangible plans that value, measure, and help manage scientists' social media engagement.

\section{Open Peer Review \\ Approval Status \\ $? \vee v$ \\ 1 \\ 2 \\ 3 \\ version 2 \\ (revision) \\ 18 May 2015 \\ version 1 \\ 09 Dec 2014
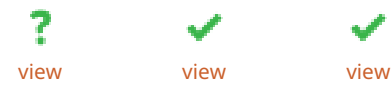

1. Paige Brown Jarreau, Louisiana State University, Baton Rouge, USA

2. Kathryn B. H. Clancy, University of Illinois, Urbana, USA

3. Sharon L. Dunwoody, University of Wisconsin-Madison, Madison, USA

Any reports and responses or comments on the article can be found at the end of the article. 
Corresponding author: Craig McClain (cmcclain@nescent.org)

Competing interests: No competing interests are declared.

Grant information: CRM is supported by the National Evolutionary Synthesis Center (NESCent), NSF \#EF-0905606.

The funders had no role in study design, data collection and analysis, decision to publish, or preparation of the manuscript.

Copyright: $\odot 2014$ McClain C and Neeley L. This is an open access article distributed under the terms of the Creative Commons

Attribution License, which permits unrestricted use, distribution, and reproduction in any medium, provided the original work is properly cited. Data associated with the article are available under the terms of the Creative Commons Zero "No rights reserved" data waiver (CC0 1.0 Public domain dedication).

How to cite this article: McClain C and Neeley L. A critical evaluation of science outreach via social media: its role and impact on scientists [version 1; peer review: 2 approved, 1 approved with reservations] F1000Research 2014, 3:300 https://doi.org/10.12688/f1000research.5918.1

First published: 09 Dec 2014, 3:300 https://doi.org/10.12688/f1000research.5918.1 


\section{Introduction}

Recently, both scientists and science communicators have issued numerous calls to the scientific community to engage in social media to both connect with other scientists (inreach) and to connect with the public (outreach). Many of the arguments made in support of using social media for science outreach (SOSM) are simply special applications of arguments for outreach in general. However, researchers often unknowingly approach engagement and outreach with a variety of counterproductive misunderstandings and assumptions, including those about whether and why their peers do or do not engage. While we are limited by the scarcity of research on this topic, we are concerned that this leads to inaccurate conceptions of the value of SOSM based in assumptions and anecdotes as opposed to data. Here, we draw upon a variety of disciplines to address what is known of the role and impact of social media on scientists.

\section{A "public relations nightmare"?}

Numerous calls for the scientific community to engage in science outreach via social media (SOSM) have been issued ${ }^{1,2}$ as part of a broader agenda for researchers to engage the public ${ }^{3-5}$. In particular, SOSM is presented as a promising new tool for science outreach in the midst of a perceived public relations crisis. Specific discussions of the public's trust ${ }^{6}$ and perceived legitimacy of scientists ${ }^{7}$ have been enfolded into a "public relations nightmare" narrative $e^{1,8,9}$. However, does science actually face diminished support or is the "public relations nightmare" an exaggeration reflecting a "institutional neurosis" of science practitioners? ${ }^{10}$

Given the prominence of vocal anti-science movements in debates around high profile issues such as vaccines ${ }^{11,12}$, climate change ${ }^{13}$, and evolution ${ }^{14,15}$ - and especially considering the intensity and frequency of personal attacks on scientists in these arenas ${ }^{16,17}$-it is reasonable to ask whether the public fundamentally distrusts scientists. Despite the coverage of these anti-science movements, polls consistently find that scientists out-perform clergy, artists, journalists, business executives, and lawyers in perceived "contribution to society" ${ }^{18}$. Even in the wake of the ClimateGate controversy, climate scientists remained more trustworthy than competing sources like weather reporters, political and religious leaders, or the mainstream media ${ }^{19}$. Scientists are in demand for media interviews, political testimony, and public address, and their influence in policy arenas "is well documented, and so is public support for this arrangement" 20 . In short, despite the evidence of growing political polarization $^{21}$, the cultural authority of organized science seems to have remained stable.

So why is the "public relations nightmare" narrative uncritically and continuously repeated? Besley and Nisbet ${ }^{22}$ argue that scientists misunderstand public attitudes - despite the available databecause they regard non-scientists as hostile "others" who are illinformed and highly susceptible to media messages, which they also perceive to be slanted against science. Some evidence does exist that these individual movements received disproportionate media coverage given their participatory numbers and impact/ importance; and, in regard to both climate change denial and antivaccine movements, that "balanced" coverage sustains the claims in the public and disproportionately favors ideas running against scientific consensus ${ }^{23,24}$. However, the tendency to lump all opposition to science, despite topic, into a common "anti-science" camp with a single root cause, rather than recognizing the diversity of motivations for challenges and rejections creates further problems ${ }^{14,25}$. This them-versus-us narrative further solidifies a group entrenchment and contempt for outsiders which ultimately develops into a deeply emotional response. Interestingly, this group mentality does not match individual perceptions of the media; scientists rate personal interactions with media highly ${ }^{22}$. With social media most scientists surveyed felt that the online public would likely benefit their career and the online audience would listen and treat them respectfully ${ }^{26}$.

\section{Are scientists engaging in social media?}

It is common to describe the scientific establishment as resistant to public engagement, and scientists tend not to believe that their colleagues actually engage in outreach ${ }^{27}$. Yet surveys suggest that scientists engage in public communication activities more often than is commonly assumed ${ }^{28}$. One survey of scientists found that nearly half of all academic scientists were engaged in some type of outreach $^{29}$ and interactions with mainstream media have become a standard expectation ${ }^{30,31}$.

Data and analyses on social media outreach are less forthcoming, but studies appear to indicate that uptake of social media by scientists is low. In a University of Michigan study, approximately $60 \%$ of the responding scientists engaged the media, public, and government agencies through traditional channels. Yet, nearly $40 \%$ of respondents stated they would never use Twitter for academic or professional work ${ }^{32}$. Wilkinson and Wietkamp ${ }^{33}$ surveyed researchers who highlighted their work in policy-relevant newsletters, reporting that, "For the majority of researchers, there has been little change in the use of [social] media to communicate with non-academic audiences over the past five years". Of the respondents, $73 \%$ had never used Twitter, 64\% had never used blogs, and 51\% never engaged online news forums. These patterns of adoption offer a strange mismatch with the expressed beliefs of nearly $44 \%$ of German and $65 \%$ of American scientists who thought that social media channels, "can strongly influence how the public thinks about science" ${ }^{34}$. It may be less a question of the platforms than intent. A 2010 survey of biology professionals and students, found that $73 \%$ of respondents did actively engage in social networking (broadly defined) as a research tool $^{35}$. A recent study ${ }^{36}$, also confirms the relatively low use of Twitter, Facebook, and Google+ compared to the active use of Google Scholar ( 60\%) and ResearchGate ( 40\%).

Until recently, we have known little about the demographics of scientists engaging in public outreach through social media. In a 2012 survey of AAAS members ${ }^{35}$, younger respondents were willing to participate in online engagement while women "were less likely to say they would be willing to write online articles, blog posts, or online responses". Previous studies suggest that career, age, and gender differences lead to differences in outreach commitment. Twice as many female $(83 \%)$ than male $(43 \%)$ graduate students were involved in outreach ${ }^{37}$. Ecklund et al. ${ }^{29}$ found that women are markedly more involved in outreach work than men (72\% versus $43 \%$ ) and marked drop offs in public engagement occurs from graduate students to postdoctoral fellows and faculty. In contrast, male and female faculty members were more equally represented in 
science outreach based on their representation in the disciplines ${ }^{37}$. Another study found that higher status and organization autonomy was also associated with greater outreach but found no effects with gender $^{38}$.

Overall, the best predictor of outreach by scientists appears to be linked to their perceptions of outreach. In general, scientists have a positive attitude toward participating in public engagement and fear associated with participation is $l^{29}$. There is also "high overall satisfaction of researchers with their own media contacts" ${ }^{30,31}$. Furthermore, scientists with more positive attitudes, higher perceived communication skills, and more formal communication training, are more likely to engage in these activities ${ }^{38}$. Increased positive views toward public outreach also increase with increasing participation in these activities ${ }^{39}$.

Perhaps the biggest obstacles to engagement with outreach in general and social media outreach specifically is a lack of time. Andrews and Weaver ${ }^{37}$ found that time constraints were the unanimous primary impediment to scientists' involvement in outreach. Participants' availability to do outreach was limited by their other priorities, which were given precedence. Ecklund et al. ${ }^{29}$ noted that for more than half of all scientists, a lack of time is the most insurmountable barrier to doing more outreach and perceived time constraints are associated with a more negative impression of doing outreach activities. For engagement with social media, Rowlands et al. ${ }^{35}$ found that the most cited inhibitor was a lack of time.

\section{Are scientists communicating through social media well?}

The view of scientists as poor communicators has been reinforced by media portrayals of scientists as eccentric and antisocial, possibly dangerous, and ultimately separate from the public ${ }^{40}$. While negative stereotypes of scientists among American adults have decreased since the 1980s, about one quarter still agree that scientists are, "odd and peculiar" ${ }^{41}$. Researchers are aware of these attitudes. Nearly $30 \%$ of scientists in one study agree that scientists are poor interpersonal communicators and more $(37 \%)$ placed the blame on scientists themselves ${ }^{29}$. However and importantly, no quantitative data or analyses support the perception that scientists are poor public communicators. We caution against the reliance on stereotypes. Arguing over anecdotal examples of scientists as both effective and ineffective communicators does little to identify legitimate deficiencies and offer effective remedies. What the scientific community desperately needs is objective studies on communication effectiveness of scientists and a clear definition of "poor communicator". One tool of this nature is that of Baram-Tsabari and Lewenstein ${ }^{42}$ that aims to assess scientists' written skills in public communication. The framework includes assessment of clarity, content, knowledge organization, style, analogy, narrative, and dialogue.

\section{Will social media outreach benefit a scientist's career?}

With regard to social media outreach, the biggest reason given in informal discussions for a scientist's involvement in social media outreach is that engagement will directly benefit a scientist's career. We feel it important to reiterate that social media is a tool that can be utilized for purposes other than public engagement. Discussion of the benefits of social media inreach (engagement within the scientific community) and outreach (engagement with the public) are muddled.

Social media may be an important tool in quickly connecting with other researchers ${ }^{36,43}$. "This is the dilemma faced by researchers in the digital age. How can we be expected to produce both quality and quantity and to yield influential research? We simply cannot-at least not on our own. Instead, we must rely on networking and collaborations to build our research programs and to remain influential in our fields in order to advance scientific knowledge. With this collaborative view in mind, scientific influence involves the body of work of both individual researchers and of research groups as a whole" 43 . Darling et al. ${ }^{44}$ demonstrated that Twitter followers for scientists were always considerably larger than their departments and these large virtual departments help to rapidly generate, share and refine ideas. Moreover blogs written by scientists for scientists are becoming common and important places for the exchange of ideas ${ }^{45}$.

In terms of social media outreach, or outreach in general, the impact on a scientist's career remains largely unquantified and quite possibly indirect. "Many faculty members identified their primary job responsibilities as research and post-secondary teaching. They felt that outreach participation hindered their ability to fulfill those responsibilities and might be an ineffective use of their skills and time, and that it was not a valid use of their research funding ${ }^{37}$ ". In the survey by Ecklund et al. ${ }^{29}, 31 \%$ of scientists felt that research university systems value research productivity, as indexed by grants and published papers, over everything else, including outreach. With this prioritization structure in place outreach may be perceived as unrelated to a scientist's academic pursuits. Additionally, the lack of funding and opportunity can make outreach labor intensive. Although social media outreach is perceived to be easy and low cost in terms of money and time, success of such endeavors may require considerable investment. Using Deep-Sea News, which garnered 2.5 million hits in 2013 as an example, the lead author spent approximately 588 hours in 2013 on social media outreach translating into 14.7 40-hour workweeks.

The "Sagan Effect" - professional stigma associated with public engagement - is perceived to be widespread ${ }^{29}$. Even those who support active engagement frequently assume that a scientist's research quality is inversely proportional to the amount of outreach work he or she does. Interestingly, Sagan's own research productivity in terms of published scientific articles remained constant, $\sim 10$ annually, throughout his career and his total scientific body of work is comparable to other eminent scientists ${ }^{46}$. However, recent changes by funding agencies, professional agencies, and scientist's views toward public outreach may help to diminish the "Sagan Effect". Moreover, the number of scientific citations is greater among French scientists who engage in greater public dissemination activities ${ }^{47}$. In terms of social media, there also appears to be an overall positive correlation between the number of citations and number of Twitter followers among scientists ${ }^{48}$.

However, one way that the social media appears not to impact a scientific career is a direct link of social media mentions and citations on a scientific article. In an analysis of 1.4 million documents 
in PubMed and Web of Science published from 2010 to 2012, Haustein et $a l .{ }^{49}$ found no correlation between a paper or a journals citation count and Twitter mentions. As argued by the authors of the study, this suggests that Twitter mentions do not reflect traditional research impact. Rather, social media mentions may capture a previously unquantified impact of a scientist's career ${ }^{50}$.

\section{Can and should SOSM be integrated into a scientist's career?}

We argue that actions and rhetoric intended to support or encourage SOSM must focus on the return on investment. For the equation to work out in favor of wide-spread and career-long engagement, we propose the following three elements are necessary:

1. It must be valued: The reward for SOSM is often seen as a direct impact on the metrics that are used in gauging scientific success, e.g. gaining tenure or earning promotion. As outlined above, the sparse data available suggest these impacts on publications, citations, and grants may be minimal and indirect. A conversation about SOSM, and outreach in general, is needed that focuses on the metrics of scientific success used by both the community and institutions and developing new ones. Recently, the University of Wisconsin-Madison Division of Biological Sciences, WI, United States, has enacted new tenure guidelines that place greater reward and priority for outreach.

"Excellence can be documented in [these] clearly defined areas, and/or through synergistic combinations of research, teaching, and outreach or service... A key component for excellence in outreach is the dissemination of information derived from scholarly inquiry for the benefit of society. Successful outreach will involve innovative practices, program developments, impacts and applications that have made continuing and substantial contributions at the local, regional, national or international level. It may also lead to transformative practices derived from clinical programs or community engagement for the benefit of society. A demonstrated capability to develop and sustain an independent, cohesive, and impactful outreach program is essential. Dossiers must include documentation of the outcomes of outreach and its impacts and, in addition, include evaluations by recognized outreach specialists in the candidate's field outside UW-Madison".

Tenure guidelines for the University of Illinois-Urbana Champaign, IL, United States, also place an increasing emphasis on "valuable public engagement" though excellence in outreach is not enough to warrant tenure.

We must expand the conversation beyond "traditional" tenure-track positions. Scientists working in the private and government sectors often do not enjoy the same freedom to actively engage the public. Scientists employed by the government are often not allowed, or highly constrained, in how they engage the public especially in the new online frontier that is social media. In the most severe case, the Environmental Protection Agency has sought to increase restriction even on those independent scientists who advise the agency, a movement opposed by journalists and scientists alike ${ }^{51}$. At the
United States Geological Service, the use of social media "to regularly talk about your area of expertise" must be "approved by Office of Communications and Publishing and your supervisor".

One area of information needed is whether institutions and scholars treat SOSM activities as actual academic and beneficial pursuits. In terms of social media as inreach, many researchers within academia may not treat blogs as serious academic products because they are not peer reviewed ${ }^{52}$. Geoffrey North in Current Biology stated, "But there is also, I think, a danger here, which lies in the very speed of response, and the way that blogs are essentially "vanity publications" which lack the constraints of more conventional publishing - they are not reviewed, and do not even have to pass the critical eye of any editor ${ }^{53}$ ".

Conversely there may be valid reasons to keep, social media, particularly inreach blogging, free from academic inclusion. Blogging may allow a circumvention of hierarchy and power dynamics of academia $^{54}$ and provide a space "distinct from the parent culture of institutions" ${ }^{55}$. In terms of both inreach and outreach, anonymity or pseudo-anonymity have often provided underrepresented groups and junior scientists the sense of security needed to discuss issues in science openly. However, while bringing needed voices to the conversation, these scientists do not get to reap any formal rewards within the halls of academia. Clearly SOSM and more generally the usage of social media require reassessment of what defines academia, scholars, scholarship, and institutions. Part of this will also have to address power dynamics in academia that prevent underrepresented groups and junior faculty from pursuing innovative online models for outreach.

2. It must be measured: We have watched with great interest the recent emergence of Altmetrics as a solution to accurately representing the totality of a scientist's scholarly impact in a webnative world ${ }^{50}$. Quantification of total downloads and social media mentions for individual scientific papers have provided an exciting advancement in measuring influence. However, these metrics do not yet capture the total social media and web presence for a researcher, e.g. blog posts or Tweets, meaning there is not yet digital equivalency for the $\mathrm{H}$-index. Furthermore, as with traditional metrics, current tools cannot discriminate between positive and negative mentions (citations), and with the dynamics of social media sharing at play, great care must be taken not to conflate 'activity' metrics with proof of influence or approval. The need to consider both quality and quantity was ostensibly the intent of the satirical attempt $^{48}$ to calculate the so-called Twitter Kardashian Index by plotting individual researchers' numbers of followers against the number of citations of their scientific output and thereby identify those who are more "famous" than their publication record merits. We find the development of a K-Index, whether in satire or not, to be counterproductive to meaningful understanding of the role of social media and fraught with methodological problems. Indeed, instead of criticizing scientists with large number of Twitter followers, we should be studying them as exemplars for that dimension of social media success.

3. It must be manageable: The most identified issue by scientists preventing them from engaging in SOSM, and outreach in general, is a lack of time. This issue remains relatively unaddressed. If the 
goal is ultimately to have more scientists engaged more fully in outreach through social media there is a need to target the conflict of the clock. One possible mechanism for this is a reprioritization and integration of research and outreach.

One way forward may be finding opportunities where effort and products can serve more than one purpose. Several existing examples demonstrate that a research program and SOSM can be integrated. For example, blog posts on scientific literature already being read for journal clubs, classes, grants, and publications represent both a way to more actively engage the literature scientifically while producing online content for public consumption. Crowd funding of science both directly engages the public while also serving as a mechanism to generate smaller funds for research ${ }^{56,57}$. Online content can also be generated as a product of classroom activities. For example, the "Sizing Ocean Giants" project (http://www.storyofsize.com/sizing-ocean-giants/), an undergraduate directed research course, focused on the body sizes of marine organisms and included a heavy social media component. Undergraduates were directed to use social media to engage the public about their specific animals, leveraging online platforms as a pedagogical tool to increase their understanding of their organisms and the scientific process. As with traditional courses, writing assignments on a variety of scientific topics were included, but these were simply migrated online as blog posts. Twitter assignments included \#sizeme where the public was encouraged to Tweet height or weight and students in the course responded with how the measurements compared to a species of marine megafauna effectively illustrating scale. Ultimately, the research by students benefited from online interactions with other scientists and lead to a peer-reviewed publication.

Many programs also exist within and outside of universities for scientists to engage in science communication and SOSM. These require less effort on the part of individual academics because infrastructure, and often training, are already in place. For example, Experiment.com provides a mechanism for scientists to launch crowd-funding campaigns. Setting out to create a new blog may not be as effective as providing a blog post to an established blog or joining a group blog.

\section{Conclusion}

We clearly need a new way to consider, conduct, and evaluate science outreach, online and off. This new model must be informed by theory and grounded in data analysis, as opposed to predicated on anecdote and assumption. We have shown here that many popular propositions about the attitudes, behaviors, and actions of scientists engaged in SOSM are incorrect. These conceptual errors may slow or impede progress by diverting efforts into solutions for the wrong problems. We propose efforts should concentrate on making SOSM a valued and worthwhile endeavor within and outside academia, an actual quantification of the value of SOSM by individuals, and creating programs that make SOSM time manageable for scientists.

\section{Author contributions \\ CRM and LN contributed equally to the conception, research, and writing of the paper.}

\section{Competing interests}

No competing interests are declared.

\section{Grant information}

CRM is supported by the National Evolutionary Synthesis Center (NESCent), NSF \#EF-0905606.

The funders had no role in study design, data collection and analysis, decision to publish, or preparation of the manuscript.

\section{Acknowledgements}

Michelle Gaither-McClain provided editorial assistance and loving patience with the first author.
1. Wilcox C: Guest editorial. It's time to e-volve: taking responsibility for science communication in a digital age. Biol Bull. 2012; 222(2): 85-7. PubMed Abstract

2. Ashlin A, Ladle RJ: Science communication. Environmental science adrift in the blogosphere. Science. 2006; 312(5771): 201. PubMed Abstract | Publisher Full Text

3. Ranganathan J: Scientists: Do outreach or your science dies. Scientific American: Guest Blog. 2013. Reference Source

4. Fiedman DP: Public outreach: a scientific imperative. J Neurosci. 2008; 28(46): 11743-5.

PubMed Abstract | Publisher Full Text

5. Reddy C: Scientist citizens. Science. 2009; 323(5920): 1405 PubMed Abstract | Publisher Full Text

6. Millstone $E$, van Zwanenberg P: A crisis of trust: for science, scientists or for institutions? Nat Med. 2000; 6(12): 1307-8. PubMed Abstract | Publisher Full Text

7. Arnoldi J: Universities and the public recognition of expertise. Minerva. 2007; 45(1): 49-61. Publisher Full Text
8. Pratt K: Science has a PR Problem. Nature's SoapBox Science. 2012. Reference Source

9. Seder S: Public Relations Nightmare: Why Are Scientists Failing to Wake People Up to Climate Change? The Contributor. 2014. Reference Source

10. Bauer MW, Allum N, Miller S: What can we learn from 25 years of PUS survey research? Liberating and expanding the agenda. Public Underst Sci. 2007; 16(1): 79-95. Publisher Full Text

11. Poland GA, Jacobson RM: Understanding those who do not understand: a brief review of the anti-vaccine movement. Vaccine. 2001; 19(17-19): 2440-5. PubMed Abstract | Publisher Full Text

12. Kata A: Anti-vaccine activists, Web 2.0, and the postmodern paradigm--an overview of tactics and tropes used online by the anti-vaccination movement. Vaccine. 2012; 30(25): 3778-89. PubMed Abstract | Publisher Full Text

13. Farmer GT, Cook J: Understanding climate change denial. In: Farmer GT, Cook J, editors. Climate Change Science: A Modern Synthesis. Dorrdrecht: Sprincer Science+Buisness Media; 2013. 445-66.

Publisher Full Text 
14. Rosenau J: Science denial: a guide for scientists. Trends Microbiol. 2012; 20(12): 567-9.

PubMed Abstract | Publisher Full Text

15. Branch G, Scots EC, Rosenau J: Dispatches from the evolution wars: shifting tactics and expanding battlefield. Annu Rev Genomics Hum Genet. 2010; 11: 317-38. PubMed Abstract | Publisher Full Text

16. Lewandowsky S: Attacks on climate scientists are the real 'climategate'. The Gaurdian. 2011.

Reference Source

17. Mann M: Climate scientists and smear campaigns. CNN. 2012. Reference Source

18. Public esteem for military still high. Washington, D.C.: PewResearch Religion and Public Life Project; 2013. Reference Source

19. Leiserowitz AA, Maibach EW, Roser-Renouf C, et al:: Climategate, Public Opinion, and the Loss of Trust. Am Behav Sci. 2012; 57(6): 818-37. Publisher Full Text

20. O'Brien TL: Scientific authority in policy contexts: Public attitudes about environmental scientists, medical researchers, and economists. Public Underst Sci. 2013; 22(7): 799-816.

PubMed Abstract | Publisher Full Text

21. Gauchat G: Politicization of Science in the Public Sphere: A Study of Public Trust in the United States, 1974 to 2010. Am Sociol Rev. 2012; 77: 167-87. Publisher Full Text

22. Besley JC, Nisbet M: How scientists view the public, the media and the political process. Public Underst Sci. 2013; 22(6): 644-59.

PubMed Abstract | Publisher Full Text

23. Brainard C: Sticking with the truth. Columbia Journalism Review. 2013. Reference Source

24. Verheggen B, Strengers B, Cook J, et al: Scientists' views about attribution of global warming. Environ Sci Technol. 2014; 48(16): 8963-71. PubMed Abstract | Publisher Full Text

25. Kahan DM: editor. Vaccine Risk Perceptions and Ad Hoc Risk Communication: An Empirical Assessment CCP Risk Perception Studies. 2014. Reference Source

26. Besley JC: What do scientists think about the public and does it matter to their online engagement? Sci Public Policy. 2014; Advanced Access: 1-14. Publisher Full Text

27. Poliakoff E, Webb TL: What Factors Predict Scientists' Intentions to Participate in Public Engagement of Science Activities? Sci Comm. 2007; 20(2): 242-63. Publisher Full Text

28. Jensen $\mathrm{P}$, Rouquier JB, Kreimer $\mathrm{P}$, et al:: Scientists who engage with society perform better academically. Sci Public Policy. 2008; 35(7): 527-41. Publisher Full Text

29. Ecklund $\mathrm{EH}$, James $\mathrm{SA}$, Lincoln AE: How academic biologists and physicists view science outreach. PLOS One. 2012; 7(5): e36240. PubMed Abstract | Publisher Full Text | Free Full Text

30. Peters HP: Gap between science and media revisited: Scientists as public communicators. Proc Natl Acad Sci U S A. 2013; 110(Suppl 3): 14102-9. PubMed Abstract | Publisher Full Text | Free Full Text

31. Peters HP, Brossard D, de Cheveigné SD, et al:: Science communication. Interactions with the mass media. Science. 2008; 321(5886): 204-5. PubMed Abstract | Publisher Full Text

32. Barteau M, Engineering C, Uhlmann D: Academic engagement in public and political discourse preliminary analysis of survey results Reference Source

33. Wilkinson C, Weitkamp E: A case study in serendipity: environmental researchers use of traditional and social media for dissemination. PLOS One. 2013; 8(12): e84339.

PubMed Abstract | Publisher Full Text | Free Full Text

34. Allgaier J, Dunwoody S, Brossard D, et al.: Journalism and social media as means of observing the contexts of science. BioScience. 2013; 63(4): 284-7. Publisher Full Text

35. Rowlands I, Nicholas D, Russell B, et al.: Social media use in the research workflow. Learned Publishing. 2011; 24(3): 183-95.

Publisher Full Tex

36. Van Noorden R: Online collaboration: Scientist and the social network. Nature
2014; 512(7513): 126-9.

PubMed Abstract | Publisher Full Text

37. Andrews E, Weaver A: Scientists and public outreach: Participation, motivations, and impediments. J Geosci Edu. 2005: 1-22.

Reference Source

38. Dudo A: Toward a Model of Scientists' Public Communication Activity: The Case of Biomedical Researchers. Sci Comm. 2012; 35(4): 476-501. Publisher Full Text

39. Martin-Sempere MJ, Garzon-Garcia B, Rey-Rocha J: Scientists' motivation to communicate science and technology to the public: surveying participants at the Madrid Science Fair. Public Underst Sci. 2008; 17(3): 349-67. Publisher Full Text

40. Nisbet MC, Scheufele Da, Shanahan J, et al.: Knowledge, Reservations, or Promise? A Media Effects Model for Public Perceptions of Science and Technology. Communic Res. 2002; 29(5): 584-608. Publisher Full Text

41. Losh SC: Stereotypes about scientists over time among US adults: $\mathbf{1 9 8 3}$ and 2001. Public Underst Sci. 2009; 19(2): 372-82. Publisher Full Text

42. Baram-Tsabari A, Lewenstein BV: An instrument for assessing scientists' written skills in public communicaton of science. Sci Comm. 2012; 35(1): 56-85. Publisher Full Text

43. Priem J, Costello KL: How and why scholars cite on Twitter. Proc Natl Acad Sci U S A. 2010; 47(1): 1-4. Publisher Full Text

44. Darling ES, Shiffman D, Côté IM, et al.: The role of Twitter in the life cycle of a scientific publication. Peer J Preprint. 2013; 6: 1-31. Publisher Full Text

45. Fox J: Can blogging change how ecologists share ideas? In economics, it already has. Ideas Ecol Evol. 2012; 5: 74-7. Reference Source

46. Shermer MB: The vew of science: Stephen Jay Gould as historian of science and scientific historian, popular scientist and scientific popularizer. Soc Stud Sci. 2002; 32(4): 489-524.

PubMed Abstract | Publisher Full Text

47. Jensen $\mathrm{P}$, Rouquier JB, Kreimer $\mathrm{P}$, et al.: Scientists who engage with society perform better academically. Sci Public Policy. 2008; 35(7): 527-41. Publisher Full Text

48. Hall N: The Kardashian index: a measure of discrepant social media profile for scientists. Genome Biol. 2014; 15(7): 424

PubMed Abstract | Publisher Full Text | Free Full Text

49. Haustein S, Peter I, Suigmoto CR, et al:: Tweeting biomedicine: An analysis of tweets and citations in the biomedical literature. J Assoc Info Sci Tech. 2014; 65(4): 656-69 Publisher Full Text

50. Priem J, Piwowar HA, Hemminger BM: Altmetrics in the Wild: Using Social Media to Explore Scholarly Impact. Literature review Methods Data collection. arXiv. 2012: 1-23.

Reference Source

51. Journalism, science groups decry EPA move to muzzle National Science Advisers. Union of Concerned Scientists; 2014. Reference Source

52. Charpentier A: Academic blogging, a personal experience. Freakonometrics 2014 Reference Source

53. North G: Social media likes and dislikes. Curr Biol. 2013; 23(11): R461. PubMed Abstract | Publisher Full Text

54. Walker J: Blogging from inside the ivory tower. In: Bruns A Jacobs J editors. Uses of Blogs. Online: Peter Lang, 2006; 1-11. Reference Source

55. Gregg M: Banal Bohemia: blogging from the ivory tower hot-desk. Convergence: Inter J Res New Media Technol. 2009; 15(4): 470-83. Publisher Full Text

56. Ingeno L: Crowdfunding academic reserach. Inside Higher Education. 2013. Reference Source

57. Wheat RE, Wang $Y$, Brynes JE, et al: Raising money for scientific research through crowdfunding. Trends Ecol Evol. 2013; 28(2): 71-2. PubMed Abstract | Publisher Full Text 


\section{Open Peer Review}

\section{Current Peer Review Status:}

\section{Version 1}

Reviewer Report 26 March 2015

https://doi.org/10.5256/f1000research.6322.r7921

(C) 2015 Dunwoody S. This is an open access peer review report distributed under the terms of the Creative Commons Attribution License, which permits unrestricted use, distribution, and reproduction in any medium, provided the original work is properly cited.

\section{Sharon L. Dunwoody}

School of Journalism and Mass Communication, University of Wisconsin-Madison, Madison, WI, USA

Readers of this opinion piece will appreciate its ability to locate and reflect on much of the recent literature dealing with the extent and perceived impact of scientists' outreach behaviors. That literature gives social media only a glancing blow, so the authors are correct to note that we know little about scientists' use of social media and about perceived and actual outcomes of such use. We do know that social media use is growing among scientists, and mainstream empirical studies - which typically generate snapshots in time that won't become available in published form for months (or years) - will have a hard time staying on the front edge of such changes. McClain and Neeley's analysis leads me to suggest that scholars pay particular attention to the impacts of social media outreach on scientists' careers. While we know that rendering one's research publicly visible via such traditional means as mass media stories has a salutary impact on the number of citations to that work in the peer-reviewed literature, we are just beginning to track the impact of scientists' "unmediated" signaling via tweets, blogs posts, etc. Some recent work found that TED talks did not appear to make much of a difference. But a very recent article in Journalism \& Mass Communication Quarterly (Liang et al., 2014) did find that, among a sample of nanoscientists, tweeting was associated with more frequent interactions with reporters and other non-scientists and that those interactions were then linked to enhanced scientific impact. I would implore the authors to "step away" from the acronyms. SOSM (science outreach via social media) deserves a quick burial. As is the case with so many acronyms, it obfuscates rather than clarifies.

Competing Interests: No competing interests were disclosed.

I confirm that I have read this submission and believe that I have an appropriate level of expertise to confirm that it is of an acceptable scientific standard.

\section{Craig McClain,}


We thank Dr. Dunwoody for their review. While we appreciate the reviewer's opinion on acronym, science outreach via social media (SOSM) was introduced for two reasons.

One, previous discussion and research in this area has confused multiple areas including lumping in use of social media of scientists as outreach. Clearly this is incorrect. We wish to specifically bring attention to a tangible issue that is at the intersection of social media usage and engaging the public and online. Specifically providing a term and acronym removes semantic issues and focuses the dialogue. Second, the acronym was introduced for pragmatic reasons. Science outreach via social media is used 20 times in the manuscript. Using the full term would make the language unwieldy for readers.

Competing Interests: No competing interests were disclosed.

Reviewer Report 20 March 2015

https://doi.org/10.5256/f1000research.6322.r7923

(C) 2015 Clancy K. This is an open access peer review report distributed under the terms of the Creative Commons Attribution License, which permits unrestricted use, distribution, and reproduction in any medium, provided the original work is properly cited.

\section{Kathryn B. H. Clancy}

Department of Anthropology, University of Illinois, Urbana, IL, USA

McClain and Neeley make an important contribution to the science communication literature with their opinion article "A critical evaluation of science outreach via social media: its role and impact on scientists." The authors do a great job dismantling many of the misconceptions held by those who naysay science communication. I also loved their manifesto at the end of the three necessary elements to support social media for science outreach (particularly the last element, which is very consistent with some initiatives on work allocation I am currently attempting at my own institution!). I have only a few comments about ways in which these authors could strengthen their manuscript:

The introduction could more clearly state the authors' argument. As experts in this field, the authors could really frame their argument for the reader by offering it from the beginning. Right now the introduction does not make clear what side of the issue for which the authors advocate.

Related to this: the headings, instead of asking the question, could just make your point. So for instance, the first could read "Science outreach is not a "social media nightmare."' For the browsing reader, making your point and THEN iterating it can be powerful.

I love how strongly cited this article is. I would love to see a little more of the extended explanation of the empirical articles to which the authors cite in their first section - they do a great job of this in the other sections.

Minor issues: 
The acronym "SOSM" appears to be out of order, since it stands for Social Media for Science Outreach (SMSO).

Personally I'm not crazy about using "impact" when the intended meaning is "effect," as is used in the title, but I leave that very minor decision up to the authors.

When there is an extended quote, it really should be turned into a blockquote so that it's clear to the reader the authors are using the words of another to strengthen their argument (examples: first and second paragraphs in right column of page 3). Though I also felt these extended quotes might be better paraphrased by the authorsso as to avoid patchwriting.

The use of the term "academic inclusion" (page 4, second full paragraph, right column) is confusing. Inclusion in academic circles is usually a term to discuss diversity initiatives. Thanks for the opportunity to review this interesting piece.

Competing Interests: No competing interests were disclosed.

\section{I confirm that I have read this submission and believe that I have an appropriate level of expertise to confirm that it is of an acceptable scientific standard.}

Reader Comment 12 May 2015

\section{Craig McClain,}

We appreciate the efforts of the reviewer to strengthen the manuscript. The main recommendation is take a stronger stance. Our goal is with the paper is not take an opinion but rather to raise specific questions and review the empirical evidence addressing these questions. Indeed, this area has been traditionally opinion rich while data poor. We specifically chose to take a more objective stance. However, we do make recommendations in the final section of the paper. We have addressed all the minor issues in our revision of the paper.

Competing Interests: No competing interests were disclosed.

Reviewer Report 18 February 2015

https://doi.org/10.5256/f1000research.6322.r7573

(c) 2015 Brown Jarreau P. This is an open access peer review report distributed under the terms of the Creative Commons Attribution License, which permits unrestricted use, distribution, and reproduction in any medium, provided the original work is properly cited.

\section{Paige Brown Jarreau}

Manship School of Mass Communications, Louisiana State University, Baton Rouge, LA, USA 
This article provides a much needed point of departure for future research regarding scientists' engagement in social media and public engagement. This article raises great questions that will need answering through future empirical evidence.

Previous studies have often queried scientists' engagement in social media and public outreach on a broad level. However, "scientists" is an extremely broad grouping. There has been some work looking at scientists' engagement in social media and public outreach by discipline and demographic variables including age and gender, but we need to go further than this. Why do some scientists make the time to engage in outreach or social media, such as tweeting and blogging, while others do not? Logistical constraints are probably involved, but are likely not the major constraint, as many extremely busy scientists find time or make time to engage in outreach via social media. How does the culture at specific organizations/institutions affect this engagement, or scientists' decisions of whether it is "worth it"? And how can social scientists uncover these nuances of behavior with regards to scientists' use of social media for outreach? I think it would be valuable it the authors addressed these questions, and addressed how future research should focus on nuances vs. overly broad descriptions of scientists' use of social media for outreach.

In the section on how social media outreach will benefit scientists' careers, the authors focus on tangible and professional benefits that are compatible with traditional measures of scientific/academic performance (such as citations and tenure). This leaves out more intangible benefits that scientists may experience from engaging in social media outreach, such as being able to see the practical applications of their research, or becoming more well-rounded in terms of their scientific expertise outside of their narrow fields of research. The authors should address how less traditional "benefits" of social media outreach can be measured and communicated to scientists in various fields. A look at the degree of collaboration that occurs for researchers who don't engage in social media vs. those who do would also be interesting.

A few other notes:

1. "the best predictor of outreach by scientists appears to be linked to their perceptions of outreach" - why isn't this explained in the context of the theory of planned behavior, or the value-belief-norm model for explaining scientists' behavior toward social media engagement / outreach?

2. "Moreover blogs written by scientists for scientists are becoming common and important places for the exchange of ideas" - I would caution against broad statements about the impacts of blogs, or what kind of blog genres are growing. In fact, there is some evidence, including from my own ongoing research (although more research is needed), that blogs geared toward outreach and explaining science to broader audience are outnumbering / growing past those blogs that are written by scientists for other scientists (these types of blogs are generally in the minority). Just as in everything else, we need more data about science blogging approaches and the impacts of those approaches. For example, which different social networks (blogs? Twitter? ResearchGate and similar science-focused social networks) are being used by researchers to talk to other researchers, and which are being used in a more outreach type of capability, and why?

I think the authors could round-out their discussion of needed research in this and related areas through a modest revision of their original article. I also encourage the authors to discuss how theories of mass communication, psychology and behavior could fit into the areas of research 
they call for.

Competing Interests: No competing interests were disclosed.

I confirm that I have read this submission and believe that I have an appropriate level of expertise to confirm that it is of an acceptable scientific standard, however I have significant reservations, as outlined above.

Reader Comment 12 May 2015

\section{Craig McClain,}

The reviewer provides many helpful suggestions for the manuscript. We thank them for the insightful review. We have addressed many of these in the article. The reviewer suggests that manuscript include more theory. Indeed, this is interesting topic and a paper that synthesizes these different field's theories and applies them to SOSM is desperately needed. Indeed, to be able to due this topic justice it would require an additional paper with multiple pages of text. This is currently beyond the scope of the manuscript. In addition, the scope of this manuscript was to specifically examine empirical evidence, and not the theory, that addresses these questions. Indeed, the impetus for the work was that several conferences talks and papers seem to ignore much of this empirical evidence.

Competing Interests: No competing interests were disclosed.

The benefits of publishing with F1000Research:

- Your article is published within days, with no editorial bias

- You can publish traditional articles, null/negative results, case reports, data notes and more

- The peer review process is transparent and collaborative

- Your article is indexed in PubMed after passing peer review

- Dedicated customer support at every stage

For pre-submission enquiries, contact research@f1000.com 